\title{
O lugar dos saberes amazônicos no ensino de literatura ${ }^{1}$ The place of Amazonian knowledge in the teaching of literature
}

\author{
Eliana Pires de ALMEIDA* \\ Secretaria de Estado de Educação (SEDUC-PA)
}

\begin{abstract}
RESUMO: A pesquisa cartografou o lugar dos saberes amazônicos no ensino da Literatura a partir de uma historiografia construída pelos teóricos da Literatura, da Sociologia do Currículo e da análise da trajetória do Colégio Estadual Paes de Carvalho. No construto dessa pesquisa foi catalogada uma experiência didática em Belém do Pará nos anos 80-90 que resultou na publicação de três livros didáticos com conteúdo regionalizado de Literatura Paraense. O estudo tem como base a Teoria Literária na perspectiva de Nunes (1998), Candido (1976), Zilberman (1989) e Barthes (2010) que apontam a Literatura como possibilidade de transmissão cultural, como fruição e como valorização da dimensão estética com vistas à cidadania. E os estudos da Sociologia da Educação e da Cultura de Bourdieu (2007) e Chartier (1996), os estudos do Currículo, com Mclaren (1997) e Moreira; Silva (1995).
\end{abstract}

PALAVRAS-CHAVE: Literatura paraense. Saberes Amazônicos. Educação. Currículo.

ABSTRACT: The research mapped the place of Amazonian knowledge in the teaching of Literature based on a historiography built by theoreticians of Literature, Sociology of the Curriculum and the analysis of the trajectory of the Colégio Estadual Paes de Carvalho. In the construction of this search, a didactic experience was cataloged in Belém do Pará in the 80-90s, which resulted in the publication of three textbooks with regionalized content from Paraense Literature. The study is based on Literary Theory from the perspective of Nunes (1998), Candido (1976), Zilberman (1989) and Barthes (2010) who point to Literature as a possibility of cultural transmission, as fruition and as an appreciation of the aesthetic dimension with a view to citizenship. And the studies of the Sociology of Education and Culture by Bourdieu (2007) and Chartier (1996), the studies of the Curriculum, with Mclaren (1997) and Moreira; Silva (1995).

KEYWORDS: Paraense literature. Knowledge of the Amazon. Education. Curriculum

\section{Introdução}

\footnotetext{
${ }^{1}$ Pesquisa defendida no Programa de pós-graduação em Educação/ Mestrado na linha de pesquisa: Saberes Culturais e Educação na Amazônia na Universidade do Estado do Pará (UEPA) sob orientação da Dra. Josebel Akel Fares e da Dra. Maria Betânia Barbosa Albuquerque com bolsa de pesquisa GM do * Conselho Nacional de Desenvolvimento Científico e Tecnológico (CNPq) no ano de 2012.

Mestrado em Educação pela Universidade do Estado do Pará (UEPA). Atualmente lotada na Secretaria de Estado de Educação, Belém/PA. E-mail: eliana_piresdealmeida@yahoo.com.br
} 
A história da Literatura Brasileira foi construída ao longo da independência política, econômica e cultural do Brasil. Na tentativa de historiar uma identidade brasileira e a produção de obras que retratassem os aspectos sociais e culturais forjou a historiografia da literatura do país. No entanto, essa historiografia nem sempre contemplou os diferentes discursos, do Norte e do Sul. Nesse sentido, a literatura produzida no país foi sendo catalogada aos poucos e o estudo de sua circulação ainda tem muito a dizer em relação a produção literária do Brasil, em especial do Norte do país. Tanto, que a literatura paraense, salvo o trabalho de Inglês de Sousa e Dalcídio Jurandir, em sua maioria continuavam desconhecidos do grande público, até os anos de 2012, ano de defesa da pesquisa que deu origem a este artigo.

No livro Crivo de Papel, de Benedito Nunes, que traz um capítulo intitulado Historiografia Literária do Brasil, o autor mapeou o firmamento da Literatura Brasileira que serviu de fonte à pesquisa.

A pesquisa do tipo documental e bibliográfica analisou fontes documentos tais como: as Leis de Diretrizes e Bases da Educação (Leis 9.394/96; 10.639/03 e 11.645/08), seus decretos, os Parâmetros Curriculares Nacionais, o planejamento curricular de Língua Portuguesa do Colégio Paes de Carvalho de 2010. Serviram também como fonte de pesquisa duas teses de doutoramento, Memórias Literárias de Belém do Pará: o grupo dos novos (1946-1952) de Marinilce Oliveira Coelho e Eternos Modernos: uma história social da arte e da literatura na Amazônia, 1908-1929 de Aldrin Moura de Figueiredo. Além, dos livros didáticos, Texto e Pretexto Experiência de educação contextualizada a partir da literatura feita por autores paraenses/Amazônicos e Do Texto ao Texto.

A pesquisa tem como perspectiva teórico-metodológica, o diálogo constante entre Literatura, Memória, História e Currículo. Sendo assim, é fundamental seguir as pistas metodológicas de Jacques Le Goff, o qual reflete o documento com o propósito de reconhecimento de uma realidade e/ou reconstituição de um tempo. O autor defende que a memória coletiva desempenha um papel importante nos estudos sociais, sendo necessária para uma prática interdisciplinar. Sobre a noção atual de documento histórico ele afirma: "Não é um material bruto, objetivo e inocente, mas que exprime o poder da 
sociedade do passado sobre a memória e o futuro: o documento é monumento" (LE GOFF, 1996, p. 10).

A abordagem do estudo levou em conta vários aspectos à formulação do que seja a recepção da Literatura, mais especificamente com vistas à Educação. A Teoria Literária, na perspectiva de Candido (1976) e Zilberman (1989), apontam a Literatura como possibilidade de transmissão de cultura, como fruição e como valorização da dimensão estética com vistas à cidadania.

Candido (1976, p.19) aponta uma possibilidade de compreender a função social da Literatura para além da análise do objeto estético, que a sociologia pretende apenas esclarecer alguns dos seus aspectos e propõe que é preciso afastar, de imediato, duas respostas tradicionais da análise do objeto estético. A primeira é, "em que medida a Arte é expressão da sociedade? E a segunda, "em que medida é social, isto é, interessada nos problemas sociais?". Para o autor, a Literatura como obra de arte possui um estatuto de comunicação que está sempre em processo. A obra literária como comunicação expressiva possui, pelo menos, três momentos nesse processo, em que os elementos indissociáveis autor, obra e público sempre estarão presentes. E que esses elementos são condicionados socialmente e, segundo o autor, a atuação dos fatores sociais depende da obra de arte.

Nesta perspectiva o estudo de Regina Zilberman (1989) em sua Estética da Recepção e História da Literatura reforça a tese de Candido (1976) no sentido em que a obra e a sociedade são condicionadas socialmente, num sistema solidário de influências recíprocas. Nesse sentido, a presente pesquisa analisou as relações de poder que nortearam as escolhas do currículo e qual o lugar dos Saberes Amazônicos na disciplina Literatura no ensino médio.

\section{Historiografia e memória literária do Brasil}

Segundo Bosi (1994), durante os ciclos mercantilistas formaram-se pequenas ilhas sociais que acabaram por dividir culturalmente e literariamente o povo brasileiro. No início, o que existia de registro eram textos de informações que os jesuítas e os viajantes relatavam sobre suas impressões da nova colônia de Portugal. Desses textos, registros conhecidos como literatura de viagens, os mais importantes são: a Carta de

Revista Moara, n. 56, vol. 2, jan-jul 2021 ISSN: 0104-0944 
Pero Vaz de Caminha à coroa portuguesa descrevendo a descoberta; O Diário de Navegação de Pedro Lopes e Sousa, que relata as experiências do primeiro grupo colonizador; O tratado da terra do Brasil e a História da Província de Santa Cruz a que vulgarmente Chamamos Brasil de Pero Magalhães; A narrativa Epistolar e os Tratados da Terra e da Gente do Brasil, do jesuíta Fernão Cardim; O tratado Descritivo do Brasil, de Gabriel Soares de Sousa; As cartas dos missionários jesuítas escritas nos dois primeiros séculos da catequese; O Diálogo sobre a Conversão dos Gentios do Pe. Manuel da Nóbrega e a História do Brasil de Fr.Vicente do Salvador. Segundo o autor, é somente a partir desse momento que há uma mudança de linguagem, quando o jesuíta passa a inserir as experiências vividas pelos colonos em suas crônicas. Há ainda, as Cartas, Informações, Fragmentos Históricos e Sermões do Pe. Anchieta.

O nascimento da historiografia literária no Brasil remonta à época da República Velha, quando o governo autorizou por meio do Decreto n. 726, de 8 de dezembro 1900, a instalação da Academia Brasileira de Letras num prédio público com vistas ao desenvolvimento da cultura e da literatura nacional. O filósofo e crítico literário paraense Benedito Nunes (1998), traçou em seu livro Crivo de papel, uma trajetória do desenvolvimento da literatura brasileira, tentando estabelecer os seus antecedentes imediatos.

Segundo o autor, a Literatura foi sendo forjada pelos historiadores no começo do século XIX, no momento em que se iniciava no país uma prática em sistematizar os documentos fundadores da nação, resultantes de muitos relatórios e diários. Isso ocorreu a partir de testemunhos documentais das expedições científicas vindas da Europa e seus tratados acerca da flora e da fauna local. As narrativas dos relatórios e diários eram minuciosas e riquíssimas em suas descrições dos aspectos culturais, ambientais e sociais.

\footnotetext{
Assim, quem conta a história da História que começa fazer-se nesse período não pode perder de vista essas duas direções, nacionalismo e historicismo, que nortearam, particularizando a união do aspecto literário e do aspecto político do mesmo movimento romântico, a formação da Historiografia brasileira em geral, alvo mobilizador de porção considerável do trabalho intelectual dessa época (NUNES, 1998, p. 214).
}

Revista Moara, n. 56, vol. 2, jan-jul 2021 ISSN: 0104-0944 
A abertura à cultura europeia se concretizou ainda mais quando D. João VI “(...) cria, ao lado de estabelecimentos científicos e cursos superiores, uma Impressão Régia e franqueia à consulta pública os 60 mil volumes da Biblioteca do Palácio da Ajuda" (NUNES, 1998, p. 207). E em 1821, quando D. João VI volta para Portugal, o então regente D. Pedro I, suspende a censura aos livros importados (AZEVEDO apud NUNES, 1998, p.208). Pois, durante os três séculos anteriores era expressamente proibido na colônia a vinda regular de estrangeiros ou a comercialização de livros importados.

Segundo o autor, a partir do pensamento dos românticos é que se direcionou grande parte dos registros dos acontecimentos e do desenvolvimento da nova nação, criando uma consciência histórica nos textos cartográficos e, consequentemente, nas narrativas literárias. $\mathrm{O}$ fato mobilizou grande parte dos intelectuais da época, que passaram a desenvolver suas atividades no campo histórico-literário.

\begin{abstract}
Não é portanto casual que a matriz de nossa História literária tenha resultado da conjunção dos esforços desses homens de letras, principalmente dos trabalhos de dois deles: Magalhães - a um só tempo "pioneiro do nacionalismo", "arauto do Romantismo brasileiro" e da "orientação francesa de nossa vida espirituall (Buarque de Holanda, 1986, p. 15), e de Varnhagen, que será o autor da esperada História do Brasil de cunho nacional. Em Magalhães, formado em medicina, a "orientação francesa" estendeu-se de seu livro de versos, Suspiros poéticos e saudades (1836). (...) Vernhagen, formado em engenharia, dedicou-se às ciências positivas, tendo estudado Paleografia antes de enveredar pela investigação histórica e de ingressar no corpo diplomático brasileiro em 1841. O Ensaio sobre a História da literatura do Brasil (1836), do primeiro, e o Ensaio histórico sobre as letras no Brasil (1847), do segundo, apareceram dentro do ciclo de investigações das fontes documentais da literatura e do passado histórico do país (NUNES, 1998, p. 216).
\end{abstract}

Os trabalhos de Magalhães e Vernhagen destacam-se entre os trabalhos relevantes à historiografia literária brasileira, por terem delimitado os esquemas cronológicos, fato fundamental à construção de uma periodização que deu suporte ao Romantismo. Porém, embora os dois tenham contribuído de forma inicial à construção da História da Literatura, os estudos de ambos se diferenciam pela abordagem das diferentes concepções que conectam a História do Brasil a uma ideologia conservadora.

O trabalho de Magalhães intitulado Ensaio foi importante, porque esboçou uma cronologia para os fatos ocorridos na Literatura em conjunto com a História do Brasil. Essa trajetória foi dividida em dois períodos, da descoberta até 1808. A principal 
contribuição do autor para a historiografia brasileira, a exemplo do que propõe Ferdinand Denis foi a valorização da "cor local", uma exaltação da natureza e da religiosidade. Já em 1836, Magalhães questiona acerca da independência ou da autonomia literária brasileira.

Os dois trabalhos relevantes de Varnhagen, O Ensaio histórico e Florilégio da poesia brasileira, retratam a visão de autores e obras da Literatura do século XVII e XVIII. A obra é narrada a partir do ponto de vista dos fatos militares, econômicos e políticos do país. Além de ilustrar o desenvolvimento das pessoas e o despontar da vida intelectual do país. Para Varnhagen, houve um atraso no desenvolvimento da atividade literária na América Portuguesa, porque para o Brasil não eram mandados os poetas, estes iam para a América Espanhola. Segundo o autor, os espanhóis conheceram à glória no campo literário antes dos portugueses, pois em 1572 foi lançado Os Lusíadas em Portugal, enquanto que, desde, 1569 já circulava no Chile a edição impressa de Araucana de Ercilla, produção de um soldado poeta espanhol. Varnhagen, produziu um registro histórico dos poetas do século XVII, no qual enaltece Gregório de Matos Guerra, como o primeiro poeta genuinamente brasileiro e reconhece Bento Teixeira como um poeta.

No Brasil Colonial, período compreendido entre 1816 a 1822, chegaram muitas missões de outros países, com a tarefa de registrar, catalogar e pintar a nova terra, entre as mais famosas estão a missão que o governo brasileiro contratou, denominada de Missão Artística Francesa, composta pelo escritor Ferdinand Denis (1798-1890), os pintores Nicolas Antoine Taunay (1755-1830) e Jean-Baptiste Debret (1798-1890) entre outros, para fundar aqui uma Academia de Belas-Artes, em 1816. Veio também a Missão Austríaca (1817) e a Missão Naturalista do Príncipe de Wied-Neuwied (17821867).

Nunes (1998), explica que outros escritores estrangeiros já haviam escrito acerca do desenvolvimento da literatura ultramarina no período de 1801 a 1819 , entre eles, o alemão Göttingen Friedrich Bouterwerk que, em uma obra coletiva de 12 volumes, apresenta uma visão panorâmica acerca das literaturas modernas produzidas no período. No tomo IV, intitulado Geschichte der Portuguesischen Poesie und Beredsamkeit inclui dois autores brasileiros: Antônio José da Silva (1705-1739) e o poeta Cláudio Manoel da Costa (1729-1789).

Revista Moara, n. 56, vol. 2, jan-jul 2021 ISSN: 0104-0944 
Outro escritor que contemplou os dois literatos brasileiros citados acima e incluiu o poeta Manoel Inácio da Silva Alvarenga foi Jean Charles Leonard Sismonde de Sismondi, que escreveu o De la littérature du midi de l'Europe em 1813. Porém, esses autores estudam a Literatura Brasileira em conjunto com a Portuguesa, como uma literatura meridional e dentro de uma "projeção ultramarina".

Enquanto que, o escritor Ferdinand Denis separa a Literatura Brasileira da portuguesa, dedicando a cada uma delas, um olhar distinto. No volume intitulado Resumo da História literária do Brasil, seguido por História literária de Portugal, já esboçava uma separação entre as duas literaturas, talvez vislumbrando uma suposta autonomia da Literatura Brasileira frente à cisão política da então Colônia (Brasil) com a sua Metrópole (Portugal).

Segundo Nunes (1998), Denis já clamava em seus estudos por uma liberdade política, os poetas deveriam se inspirar no espírito livre dos indígenas e na exuberância da natureza para brotar de suas entranhas a essência do brasileiro. Direito que, de acordo com Denis, só os nascidos aqui poderiam garantir frente a uma hierarquização imposta pelo governo português na nova terra. Denis foi considerado o precursor do indianismo romântico, com a obra Scènes de la Nature, onde escreve uma novela de nome Machakalis, em que exalta a natureza exuberante do Brasil e suas gentes. Paisagem, que, segundo o autor, se contemplada pelos românticos de outrora, daria aos escritores locais munição para criar uma estética própria, desvinculada das influências europeias e do esplendor grego.

Os estudos de Nunes (1998), a partir deste ponto, coadunam com os estudos de Zilberman (2009), asseverando que o primeiro historiador que narrou o desenvolvimento da Literatura Brasileira foi Ferdinand Denis. Para Zilberman (2009), Denis produziu um mapeamento das produções literárias do Brasil, em que testemunhou uma mestiçagem do conhecimento português com os cenários e saberes indígenas em prosa e verso. Essas narrativas produzidas desde o descobrimento do Brasil até a época da Independência, citam, entre outros, os escritores Cláudio Manoel da Costa, Tomás Antonio Gonzaga, Antônio Pereira de Sousa Caldas, o Frei José de Santa Rita Durão e José Basílio da Gama.

No período de 1870 a 1879, existiu uma revista chamada $O$ Novo Mundo, que era produzida na cidade de Nova York, e tinha o poeta Joaquim de Souza Andrade, o 
Souzândrade ${ }^{2}$, como diretor. A revista se propunha a apresentar um mapeamento do progresso da política, da literatura, da arte e da indústria no Brasil. No ano de 1873, Machado de Assis publicou nessa revista um ensaio denominado de "Notícia da atual literatura brasileira", em que contestava o viés adotado pela produção literária brasileira.

\begin{abstract}
Sente-se aquele instinto até nas manifestações da opinião, aliás mal formada ainda, restrita em extremo, pouco solícita, e ainda menos apaixonada nestas questões de poesia e Literatura. Há nela um instinto que leva a aplaudir principalmente as obras que trazem os toques nacionais. A juventude literária, sobretudo, faz deste ponto uma questão de legítimo amor-próprio. Nem toda ela terá meditado os poemas de Uruguai e Caramuru com aquela atenção que tais obras estão pedindo; mas os nomes de Basílio da Gama e Durão são citados e amados, como precursores da poesia brasileira. A razão é que eles buscaram em roda de si os elementos de uma poesia nova, e deram os primeiros traços de nossa fisionomia literária, enquanto que outros Gonzaga por exemplo, respirando aliás os ares da pátria, não souberam desligar-se das faixas da Arcádia nem dos preceitos do tempo. Admira-selhes o talento, mas não se lhes perdoa o cajado e a pastora, e nisto há mais erro que acerto (ASSIS apud ZILBERMAN, 2009, p.55).
\end{abstract}

Os primeiros intelectuais brasileiros, os ditos "homens de letras", os primeiros escritores que produziram efetivamente uma narrativa literária migraram de suas localidades em busca de formação. Alguns, tiveram uma refinada educação religiosa e humanística, em sua grande maioria forjada nos colégios da Companhia de Jesus, uma espécie de franquia educacional oferecida pela Igreja ao governo do Brasil. Sabe-se que, o espírito inovador dos românticos, não foi o responsável pela independência política, mas uniu o desejo de liberdade política e literária do Brasil.

Na região amazônica, o desenvolvimento intelectual não aconteceu diferente do resto do país e Belém no século XVIII viveu um apogeu econômico e cultural:

Na Amazônia do século XIX, edificar era dominar a natureza, abrir as portas
da região ao progresso, à civilidade, à higienização e à ordenação das
cidades, significando o combate aos costumes considerados atrasados da
população. Por este prisma, construir teatros, museus, bibliotecas, escolas,
para citar alguns prédios públicos, era um projeto político de modernidade.
Na região, esse projeto começara no século XVIII, quando Belém teve seu
poder político e econômico ampliado sob os auspícios da Coroa Portuguesa,
no plano estratégico de assegurar o domínio da parte setentrional de seu
território no Novo Mundo - lembrando que, até 1823, o então Estado do
Grão-Pará e Rio Negro era administrado diretamente pela Coroa, não

${ }^{2} \mathrm{Na}$ revisão da história da Produção Literária brasileira Sousândrade é tido como um legítimo representante das injustiças literárias em nosso país, autores esquecidos que viveram à margem, no caso dele, só lido e reconhecido depois de morto.

Revista Moara, n. 56, vol. 2, jan-jul 2021 ISSN: 0104-0944 
integrando o Estado do Brasil, condição adquirida apenas com a Adesão do Pará à Independência, em 15 de agosto de 1823 (SOUZA, 2010, p.79) 20.

No entanto, poucas obras e poucos autores amazônicos são citados nas historiografias literárias nos séculos XVIII e XIX. Segundo Pressler (2009), José Eustachio de Azevedo, seria o primeiro historiador e crítico da literatura brasileira que se manifestou contra a exclusão da produção paraense-amazônica. $\mathrm{O}$ autor ressalta que nesse período eram poucas as obras literárias de autores amazônidas que circulavam nacionalmente.

[...] à primeira vista, poucas obras literárias na região da Amazônia [01]: $A$ Muhuraida (1785/1819), Sima. Romance Histórico do Alto Amazonas (1857) e os romances de Inglês de Sousa, o mais conhecido, O Missionário (1891). O poema épico de Henrique João Wilkens ficou despercebido diante das obras de Basílio da Gama e Santa Rita Durão. Lourenço da Silva Araújo Amazonas publicou Sima "no mesmo ano [...] de $O$ Guarani, de José de Alencar, que oficialmente foi o romance a criar essa vereda romântica no Brasil". Não há circulação nacional destas obras. Despercebida também a obra do maranhense Sousândrade (Joaquim de Sousa Andrade). A primeira publicação ocorreu no Rio de Janeiro, também em 1857, depois em Nova York, em 1874; o canto amazônico "Tatuturema" foi publicado em Londres, em 1888. Enquanto os maranhenses Gonçalves Dias e Aluísio Azevedo, desde o início da sua produção literária, foram incluídos na literatura brasileira. Nomes de paraenses e amazonenses como Bento de Figueiredo Tenreiro Aranha (1769-1811), Dom Romualdo Antonio de Seixas (17871860), Felipe Patroni (1794-1865), Frederico José de Santa-Anna Nery (1848-1901) e José Eustachio de Azevedo (1867-1943) não ultrapassam o limite local (Belém/Pará) e do conhecimento de especialistas — ou são desvinculados da região amazônica como José Veríssimo (1857- 1916). [...] A obra prima do único autor do Norte reconhecido na História da Literatura Brasileira, Herculano Inglês de Sousa, O Missionário (1891), é canonizada romance naturalista, mas os demais romances do autor, O Cacaulista (1876) e O Coronel Sangrado (1877), e a antologia Contos Amazônicos de 1893 não ultrapassam a circulação regional e não são valorizados pela crítica, mesmo que A História de um Pescador (1876) expressa as características do Romantismo. Ele é na região Norte para a crítica, ausente. Ressalta-se a importância da literatura do Naturalismo considerado somente a partir do romance $O$ Mulato (1881), do maranhense Aluísio Azevedo. Somente o Ciclo de Borracha (1880-1912) permitiu um salto enorme da região em relação ao crescimento econômico e cultural. A crítica reconhece uma representação literária inicial, mas - ao mesmo tempo - se encerrou definitivamente não só a escola romântica como também a parnasiana e a simbolista existentes na Amazônia, de pouca importância para o olhar nacional. Na pauta do dia estava o Modernismo e, não por acaso, Macunaíma que nasceu na região amazônica. (PRESSLER, 2009, p.1-2).

Vale ressaltar, que José Eustachio de Azevedo em seu livro Literatura Paraense de 1922, traz uma pista importante para a historiografia literária brasileira, o crítico elenca a fundação da Associação Mina Literária, que aconteceu em janeiro de 1895

Revista Moara, n. 56, vol. 2, jan-jul 2021 ISSN: 0104-0944 
com foco no desenvolvimento da literatura feita na Amazônia, como o evento que antecedeu a fundação da Academia Brasileira de Letras, que só aconteceria em dezembro de 1896.

Na história da Literatura Brasileira existem vários manifestos publicados, como o Manifesto da Poesia Pau-Brasil e o Manifesto Antropofágico da Semana de 1922, que exaltavam a literatura produzida no país. Alguns nunca foram veiculados nos jornais e revistas especializadas e foram esquecidos do cânone nacional. Um exemplo disso é o manifesto Flami-n'-Assú, de Abguar Bastos que, segundo Figueiredo (2001), é o mais original dos manifestos produzidos na Amazônia nos anos 1920. O manifesto aos intelectuais paraenses foi escrito no Acre e, posteriormente, publicado em duas revistas culturais do Pará, A Semana e Belém Nova. O documento clamava por uma "independência" à produção literária da Amazônia e ousadamente, questionava o manifesto de Oswald de Andrade.

$\mathrm{O}$ grito de Abguar respondia, como manifesto, às principais exigências de uma concepção de história fundada em dois grandes mitos: a mudança e a origem. A transformação em relação ao passado e a origem brasílica. Antes de mais nada, tornou-se fundamental o lugar do discurso: "porque eu vos falo da ponta dum planalto amazônico, entre selvas, uiras e estrelas\| enfatizava o literato, invocando a autoridade de um ser autóctone que sonhava com a "liberdade literária". No lugar de uma tribuna acadêmica, Abguar preferia gritar ao pé de uma grande sapopema. Entrava em questão não apenas o anseio de uma arte nacional, mas a necessidade de construir um léxico brasílico, fundado numa espécie de síntese "indo-latina”. (...) O manifesto era assim dirigido a dois grupos intelectuais muito distintos: os parceiros de Abguar e os velhos, então "apajelados à sombra das vossas tabas primitivas e que estais a ver, espetados em paus sagrados, os despojos, as glórias, as caveiras "das vossas escaladas às cordilheiras da ilusão". Ambos teriam que tomar consciência de uma nova "corrente de pensamento" que tomava corpo no Sul do país com "pele genuína" - o movimento - Pau-Brasil. (...) Abguar Bastos tinha, no entanto, alguns senões a respeito do manifesto de Oswald de Andrade. De fato, não obstante o "repique" que Pau-Brasil havia conseguido na modorrenta literatura pátria, ainda não era o melhor exemplo do "volume da nacionalidade" brasileira. Faltava o fundo gentílico e o traço ético, por isso "o título incisivo flami-n'-assú", ou "a grande chama indo-latina", símbolo-mor para o presente e para o futuro" (FIGUEIREDO, 2001, p. 26667).

Segundo Furtado (2009), há uma variedade de escritores que "retrataram literalmente a Amazônia brasileira" e que foram reconhecidos nacionalmente e internacionalmente. Cabe lembrar que não apenas amazônidas produziram narrativas com essa temática, estrangeiros também o fizeram:

Revista Moara, n. 56, vol. 2, jan-jul 2021 ISSN: 0104-0944 
(...) há nomes de variados estados que atingiram reconhecimento nacional, como o fluminense Euclides da Cunha, o gaúcho Raul Bopp, o paulista Mário de Andrade, o potiguar Peregrino Júnior, o pernambucano Alberto Rangel, além do português Ferreira de Castro. Há, ainda, autores locais que ultrapassaram as fronteiras nativas e galgaram espaço nas regiões sul e sudeste, inscrevendo seus nomes nas Histórias da Literatura Brasileira, como os paraenses Inglês de Sousa, Abguar Bastos, Osvaldo Orico, Raimundo de Moraes, Dalcídio Jurandir, e, mais recentemente, os amazonenses Márcio Souza e Milton Hatoum (FURTADO, 2009, p. 77)

Nesse sentido, Dalcídio Jurandir, Lindanor Celina, Bruno de Menezes e Eneida de Moraes foram autores que tiveram seus textos em circulação em livros didáticos no estado e nacionalmente. Um exemplo disso está na Antologia Escolar de Escritores Brasileiros de Hoje (ficção), organizada por Renard Pérez e publicada na década de 1980 no Brasil. Nela consta um fragmento do livro Belém do Grão-Pará, de Dalcídio Jurandir que está ao lado de escritores já consagrados pela crítica literária brasileira, fato raro para um nortista até esse período.

\section{Os aspectos legais e sociológicos da disciplina literatura}

A discussão sobre o ensino da disciplina Literatura no país é anterior à aprovação da primeira Lei de Diretrizes e Bases da Educação (Lei n. 4.024/61). Vale ressaltar, que o ensino no país só muito recentemente foi pensado com vistas a uma educação que contemplasse os diferentes saberes das regiões do Brasil. A unificação da língua, como sistema simbólico na construção da identidade cultural nacional por meio da educação é uma proposta recente.

O ensino no país é regido pela Lei n. 9.394/96 - Lei de Diretrizes e Bases da Educação Nacional (LDB), pelos Parâmetros Curriculares Nacionais (PCN's) e pelos Programas aprovados pelo Conselho Estadual de Educação do Pará. A Lei assegura uma educação preocupada com os estudos dos saberes culturais e a disciplina Literatura, A educação deve abranger os processos formativos que se desenvolvem na vida familiar, na convivência humana, no trabalho, nas instituições de ensino e pesquisa, nos movimentos sociais e organizações da sociedade civil e nas manifestações culturais. Tanto para a formação inicial, quanto para a formação continuada.

O Congresso Nacional ao aprovar o Plano Nacional de Educação (PNE) emitiu um parecer no ano de 1998, em que afirmava que o processo de modernização pelo qual 
o país passava, exigia dele um sistema educacional mais eficiente, que acompanhasse o desenvolvimento do Brasil. O Ensino Médio, ganhou um importante papel a desempenhar, como forma de possibilitar aos alunos, inserção nos saberes locais, à cultura e à literatura como forma de expressar sua cidadania, seu mundo, sua realidade.

A Lei $n^{\circ}$. 11.645, de 2008, estabelece as diretrizes e bases da educação nacional, para incluir no currículo oficial da rede de ensino a obrigatoriedade da temática "História e Cultura Afro-Brasileira e Indígena" que devem ser ministrados no âmbito de todo o currículo escolar, em especial, nas áreas de Educação Artística, Literatura e História brasileira.

O ensino da Arte é estabelecido pela Lei nº $12.287 / 10$ que traz em sua redação a determinação de que as expressões regionais constituam componente curricular obrigatório nos diversos níveis da Educação Básica, de forma a promover o desenvolvimento cultural dos alunos e a formação continuada dos professores.

Desse modo, a Educação deve ser ampla e estar vinculada ao mundo do trabalho e à prática social do educando. No artigo $9^{\circ}$, da LDB, a União fica incumbida, em colaboração com os estados, o Distrito Federal e os municípios, de estabelecer competências e diretrizes para todos os níveis de ensino, que nortearão os currículos nos conteúdos mínimos.

No que concerne à incumbência dos estados, a lei determina que elaborem e executem políticas e planos educacionais, em consonância com as diretrizes e planos nacionais de Educação, visando à integração de suas ações com os municípios. No entanto, a elaboração e execução da proposta pedagógica é de responsabilidade do estabelecimento de ensino, respeitadas as normas comuns e as do seu sistema de ensino.

A Literatura, neste sentido, promove uma chance de conhecer outras realidades por meio da recepção das narrativas ficcionais, da poesia e dos contos. Experiência capaz de despertar no aluno/leitor aproximações com as suas vivências e as suas demandas, seus atravessamentos e contribuir com sua formação biopsicossocial.

Bourdieu (2007) propõe que a Educação e a Cultura devem caminhar lado a lado para um melhor desenvolvimento do aluno. $\mathrm{O}$ autor debate as diferentes abordagens acerca das funções e do funcionamento social dos sistemas de ensino na sociedade contemporânea e analisa os diferentes grupos sociais, suas relações com a Escola e com

Revista Moara, n. 56, vol. 2, jan-jul 2021 ISSN: 0104-0944 
os diferentes Saberes. O autor faz uma análise das condições de produção e de distribuição dos bens culturais e simbólicos na sociedade.

Barthes (2010) dividiu em dois momentos o processo de significação na Semiótica, em denotativo e conotativo. O primeiro termo trata da percepção simples ou superficial; e o segundo está relacionado aos sistemas de códigos que são transmitidos e adotados nos veículos de comunicação. Esses dois processos aliados aos textos literários promovem no aluno/leitor benefícios capazes de coadunar com a sua formação.

Chartier e Bourdieu (1996), em Práticas da Leitura, apontam um possível caminho para se compreender o estatuto da leitura através dos tempos e sua aproximação com a Escola. Bourdieu (1996) afirma que há necessidade de se entender a leitura como um consumo cultural, ou seja, compreender o texto literário como um bem cultural a ser adquirido e repassado em sala de aula. Bourdieu (2007), em Escritos de educação, postula a necessidade de a escola desenvolver eficazmente a aptidão dos alunos para as práticas culturais. A Escola, para o autor, é o espaço legítimo de aprendizagem da cultura erudita, espaço de conhecimento do código e dos fenômenos de difusão cultural necessário à formação cultural e educacional.

\footnotetext{
Os educandos provenientes de famílias desprovidas de capital cultural apresentarão uma relação com as obras de cultura veiculadas pela escola que tende a ser desinteressada, laboriosa, tensa, esforçada, enquanto para os indivíduos originários de meios culturalmente privilegiados essa relação está marcada pelo diletantismo, desenvoltura, elegância, facilidade verbal “natural" (BOURDIEU, 2007, p.6).
}

O educador francês Jean-Claude Forquin (1992), em Saberes escolares, imperativos didáticos e dinâmicas sociais, trabalha a Sociologia da Educação com vistas à cultura escolar, com atenção especial à "transmissão de saberes e de símbolos" (FORQUIN, 1992, p.15) contidos no conteúdo curricular. O autor analisa as relações de poder presentes na escolha dos saberes a serem repassados na Escola, nesse espaço de reprodução de uma ordem social estabelecida e, ao mesmo tempo, um espaço de transformação social.

Mclaren (1997) estuda as questões da Pedagogia e da Educação Pós-Moderna, com vistas a uma escola mais crítica e preocupada com à diferença. Sua obra visa uma pedagogia mestiça, híbrida, que busca uma educação para além da simples reprodução dos saberes, e luta por reformas educativas em direção à equidade entre os sujeitos, por meio de um currículo multicultural.

Revista Moara, n. 56, vol. 2, jan-jul 2021 ISSN: 0104-0944 


\section{Currículo de Língua Portuguesa e Literatura no colégio Paes de}

\section{Carvalho}

A pesquisa de base sociológica, centrou atenção nos conteúdos selecionados no currículo e buscou compreender o currículo como agente constitutivo da formação dos alunos. Nesse sentido, levou-se em consideração a organização e o planejamento do currículo da disciplina Língua Portuguesa/Literatura do ano letivo de 2010, tendo como locus da pesquisa o Colégio Estadual Paes de Carvalho.

No planejamento curricular integrado da instituição os objetivos de 9 (nove) professores foi melhorar a qualidade do ensino das disciplinas Língua Portuguesa, Literatura e Produção Textual, por meio de uma prática docente reflexiva e crítica. Bem como, trabalhar os conteúdos através de um estudo contextualizado, sendo a leitura e a escrita seus objetivos principais. Outra questão proposta por eles foi a de trabalhar com os aspectos gramaticais, acidentais e periféricos necessários à compreensão da Língua falada e escrita, valendo-se da interdisciplinaridade como estratégia de ensino.

Os professores elencaram como sugestões alguns procedimentos metodológicos que podiam ser modificados e adaptados, conforme as habilidades a serem alcançadas em cada turma. Entre eles estão: a leitura e a discussão de textos diversos, aula expositiva, uso de multimídia, de filmes para intensificar o conteúdo ministrado em sala de aula, a aplicação de exercícios individuais, a aplicação de exercícios em dupla ou em grupos maiores para que haja, posteriormente, uma socialização das respostas, leitura conjunta e comentada de um texto, seminário sobre um dos conteúdos, palestra com escritores paraenses, visitas aos Museus, à Bibliotecas, à Exposições, à Feiras, etc.

Para alcançar os objetivos traçados no planejamento curricular, os professores lançaram mão de vários recursos pedagógicos, como: livro didático, apostilas, exercícios programados, paradidáticos das leituras obrigatórias no Processo Seletivo (PROSEL) e no Programa de Ingresso Seriado (PRISE), entre outros. A avaliação deveria constar de: prova objetiva e analítico-discursiva, seminário, trabalho em grupo, simulado, debate, exercício individual e observação (disciplina, comportamento, interesse, participação, atenção, domínio dos conteúdos e relevância nos comentários).

Revista Moara, n. 56, vol. 2, jan-jul 2021 ISSN: 0104-0944 
Os conteúdos propostos visavam integrar as habilidades e competências das disciplinas Língua Portuguesa, Produção Textual, Literatura Portuguesa e Brasileira para os três últimos anos da Educação Básica e foram divididos em bimestres. No entanto, para a pesquisa em questão foi analisado apenas os conteúdos da disciplina Literatura Brasileira. Com o objetivo de analisar quais conteúdos foram privilegiados e quais foram silenciados no documento, com o objetivo de perceber o lugar dos saberes amazônicos no planejamento da disciplina Literatura.

No planejamento curricular analisado foi usada a cronologia da Literatura Portuguesa e Brasileira, os professores concebem, inclusive, como "o ensino da Literatura Luso-Brasileira". Observou-se que os conteúdos propostos para o ensino da disciplina Literatura no documento analisado não levavam em considerações as diretrizes legais, que ordenam que o conteúdo curricular seja adaptado para fazer valer a diversidade cultural de cada região do país. Essa prerrogativa visa aumentar o estímulo a criticidade e ampliar o repertório sociocultural do alunado. Foi mapeado diversos textos canônicos da literatura Portuguesa e Brasileira para o Ensino Médio. No entanto, os saberes amazônicos presentes no planejamento dizem respeito apenas a leitura obrigatória para os processos seletivos seriados, há uma observação no planejamento do $2^{\circ}$ e $3^{\circ}$ anos em que se lê: "Aguardando ajuste de conteúdo (Leituras obrigatórias) dos Vestibulares". E para o 4 bimestre do $2^{\circ}$ ano o único autor paraense elencado foi Inglês de Souza com Contos Amazônicos (1893), com apenas 4 contos contemplados. A ausência dos saberes amazônicos no planejamento escolar da disciplina foi flagrante, mesmo que as leis educacionais do Brasil exijam esse ensino multicultural no planejamento curricular de suas instituições.

Segundo Moreira; Silva (1995), quando emergiu e se desenvolveu a Nova Sociologia da Educação (NSE), na virada do século XX, muitas correntes surgiram em diferentes países. Mas, comum a todas elas, havia a preocupação com os processos de racionalização, sistematização e controle da Escola e do Currículo. Pois, é notório que o currículo é socialmente constituído pelas relações de poder no interior da Escola e pela sociedade que o cerca.

O contexto da pesquisa foi o Colégio Paes de Carvalho, a instituição educacional mais antiga do estado do Pará e segunda mais antiga do Brasil, foi criado pela Lei n. 97, de 28 de junho de 1841, pela Assembleia Legislativa, que tinha como presidente da 
província do Grão-Pará, o Dr. Bernardo de Souza Franco. Originalmente batizado de Lyceu Paraense, passou a Gymnasio Nacional até chegar ao nome atual de Colégio Estadual Paes de Carvalho.

França (1997), ressalta que as Escolas de Primeiras Letras foram criadas pela Lei Geral de Instrução Pública, regulamentada em 1827. Pouco tempo depois é instituído o Ato Adicional de 1834 pelo poder central, que repassa o encargo de criar e manter escolas primárias aos governos regionais, fato que ocorreu somente no ano de 1841 na província do Grão-Pará.

Segundo Rego (2002), após as reformas na área educacional na década de 1970, os antigos cursos Primário e Ginasial transformaram-se em $1^{\circ}$ Grau e os antigos cursos colegiais transformaram-se em $2^{\circ}$ Grau. E o colégio foi transformado em Escola Estadual de $2^{\circ}$ Grau Paes de Carvalho. No entanto, como havia uma rivalidade antiga entre os alunos do Colégio Estadual Paes de Carvalho (CEPC), conhecidos como "xaréus", e os alunos do Instituto de Educação do Pará (IEP), conhecidos como "piramutabas", foi aprovado um projeto de Lei pela Assembleia que instituiu os tradicionais nomes das instituições centenárias de ensino, como o Colégio Estadual Paes de Carvalho e o Instituto de Educação do Pará. Em um breve levantamento da condição histórico-pedagógica deste Colégio percebeu-se que a instituição, desde seus primórdios, ainda como Lyceu, já tinha no estudo da disciplina Língua Portuguesa um de seus principais pilares rumo a uma educação com vistas às Humanidades, inclusive criando um bacharelado em Ciências e Letras que contemplava matérias de Língua Portuguesa, Literatura, Línguas Estrangeiras, Latim, Retórica e Poética.

Rego (2002) e França (1997) apresentam em suas pesquisas, uma mostra dos planejamentos curriculares praticados no Colégio Estadual Paes de Carvalho ao longo de sua história. Nos dois estudos foi possível verificar uma notável vocação da instituição às Letras, ao ensino da disciplina Língua Portuguesa e da disciplina Literatura.

\section{Dos Saberes Amazônicos em livros didáticos}

Na prefeitura de Belém, no ano de 1988, a partir de uma política pública municipal e posteriormente, estadual, motivada pela luta de professores da rede básica de ensino 
foram elaborados livros didáticos que contemplavam a Literatura Paraense ou Literatura de Expressão Amazônica em seu conteúdo. Foram editados os livros Texto e Pretexto: Experiência de educação contextualizada a partir da literatura feita por autores paraenses, Texto e Pretexto: Experiência de educação contextualizada a partir da literatura feita por autores amazônicos e Do Texto ao Texto: Leitura, Gramática e Criação, todos de autoria de Fares, J. et al.

Figura 1: Capas da segunda edição

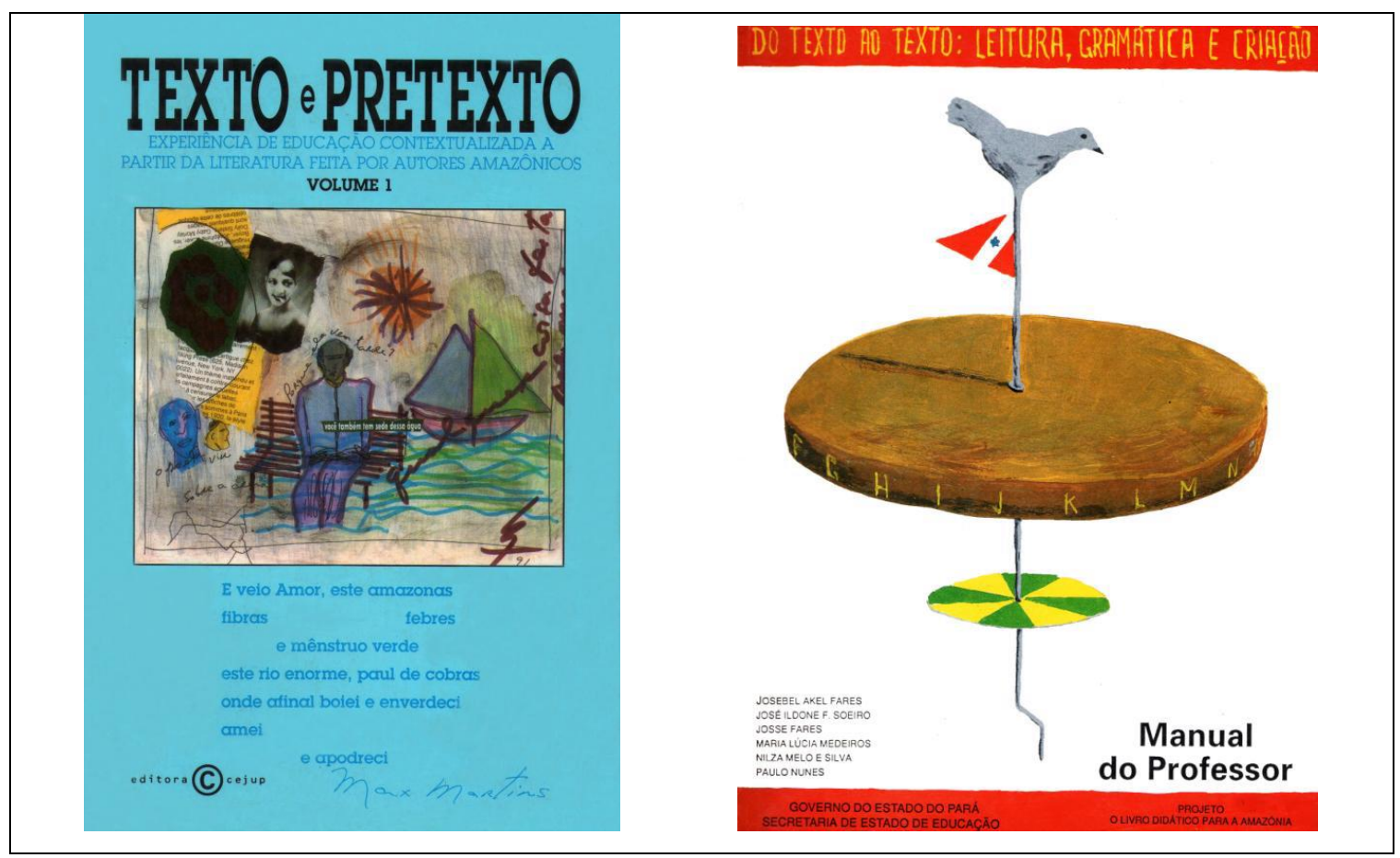

Fonte: Biblioteca da Dra. Josebel Akel Fares. Foto: Eliana Pires

A regionalização do currículo foi uma ação implementada pela Secretaria Municipal de Educação e Cultura (SEMEC), pelo então, secretário João de Jesus Paes Loureiro por meio da Proposta Modular de Educação e Cultura. Essa ação buscava inserir em sala de aula, especificamente na área de Língua Portuguesa, alguns textos literários produzidos por escritores paraenses ou não, mas que tinham em comum, os Saberes Amazônicos em suas narrativas.

Segundo os autores do livro, o ato de elaborar um livro didático que pudesse satisfazer professores e alunos numa região multicultural como a nossa, não foi tarefa fácil. Na apresentação do livro os autores descrevem o passo a passo do processo de elaboração dos conteúdos e dos exercícios propostos, os quais resguardavam a cultural

Revista Moara, n. 56, vol. 2, jan-jul 2021 ISSN: 0104-0944 
regional, com textos de autores paraenses ou amazônicos. Entre eles: Bruno de Menezes, Eneida de Moraes, Dalcídio Jurandir, Lindanor Celina, Rui Barata, João de Jesus Paes Loureiro, Ápio Campos, Haroldo Maranhão, Juraci Siqueira, Heliana Barriga, Hélio Melo (acreano), Thiago de Mello e Márcio Sousa (amazonenses).

\section{Considerações finais}

O percurso histórico desenvolvido até aqui foi necessário para evidenciar a importância da historiografia Literária Brasileira e como atuam as leis educacionais em relação à disciplina Literatura. Especificamente, buscou-se verificar qual o lugar dos Saberes Amazônicos no ensino da disciplina Literatura. Pois, alguns pesquisadores buscam pistas dos amazônidas em narrativas literárias, na tentativa de reconhecer o povo da floresta na Arte Literária Brasileira. Dessa forma, este estudo pretendeu dar visibilidade a alguns trabalhos e pesquisas que buscaram sistematizar a trajetória da Historiografia Literária Brasileira, com enfoque especial na Literatura Paraense ou Amazônica.

De acordo com os estudos sociológicos, pedagógicos e culturais cabe ao jovem buscar seu "capital cultural pela magia coletiva", pela assimilação, pela interação ou pela incorporação de valores à sua cultura. No entanto, é necessário que a escola promova a aquisição da competência leitura e promova debates com vistas à uma cidadania emancipatória para esses alunos. E, neste caso, a disciplina Literatura desenvolve essa tarefa facilmente, pois, agrega em suas narrativas ficcionais, debates oportunos referentes às questões culturais e sociais de uma época. A disciplina é entendida aqui como um saber cultural carregado de significados e símbolos, que estabelecem, sistematicamente, diferentes categorias sociais no campo educacional.

A Literatura sendo ciência e arte, não poderia deixar de ter relações com os outros ramos do saber humano, pois há entre elas uma íntima correlação de saberes. Ao analisar os diferentes documentos que normatizam e direcionam o ensino da disciplina Literatura no Brasil, percebe-se que, talvez por não estar disposta de forma autônoma no Ensino Fundamental e Médio, a disciplina acabe por deixar em segundo plano alguns aspectos específicos da Literatura. Como, por exemplo, os aspectos estéticos e o próprio fruir do texto literário, necessário para experiência do aluno/leitor.

É fundamental ressaltar o valor histórico e testemunhal da disciplina Literatura para o ensino, seja na formação de jovens leitores ou de professores. Pois, a partir dos textos literários

Revista Moara, n. 56, vol. 2, jan-jul 2021 ISSN: 0104-0944 
é possível que o aluno/leitor amplie a sua formação cultural e intelectual. É preciso reafirmar que a disciplina Literatura abarca o campo da memória, da história e da cultura. Elementos essenciais à formação cidadã de todos os envolvidos no processo de ensino-aprendizagem.

Nesse sentido, concluímos a partir da análise do currículo do Colégio Paes de Carvalho de 2010 que, aparentemente, ainda foi pensado para que os alunos aprendessem a respeitar as igualdades e não a diferença. Privilegiando os conteúdos canônicos, os quais são distantes da realidade do aluno/leitor do Norte, em detrimento dos Saberes Amazônicos. Percebeu-se que, mesmo na contemporaneidade, o currículo tende a ser monocultural e homogeneizador. Fato que evidencia a necessidade de que os saberes hegemônicos sejam decolonializados no interior da escola e em seu currículo. Fazendo valer o ordenamento jurídico educacional do Brasil.

É notório que a Literatura e as Artes ajudam os alunos a perceberem o mundo com um olhar diferenciado e, consequentemente, a produzirem textos melhores. A obra literária é reconstituição de um tempo, de uma época, é memória e, por isso, História.

\section{REFERÊNCIAS}

ALBUQUERQUE, M.B.B. Trilhas e temas da disciplina filosofia da educação a partir da PUC-SP. 2002. Tese (Doutorado em Educação: História, Política, Sociedade), Pontifícia Universidade Católica de São Paulo, São Paulo, 2002.

AZEVEDO, J.E. Literatura Paraense. $3^{\text {a }}$ Ed. Belém: FCPTN/SECULT, 1990.

BARTHES, R. O prazer do texto. 5 ed. São Paulo: Perspectiva, 2010. (p.18)

BOSI, A. História Concisa da Literatura Brasileira. 48ª ed. Cultrix: São Paulo, 2006.

BOURDIEU, P. Escritos de Educação. In: NOGUEIRA, A.N.; CATANI, A.(Orgs). Escritos de educação. Petrópolis: Vozes, 2007.

CANDIDO, A. Literatura e Sociedade: estudos de teoria e história literária. 5. ed. revisada. São Paulo: Ed. Companhia Editora Nacional, 1976.

BOURDIEU, Pierre; CHARTIER, Roger. A leitura: uma prática cultural. Debate entre Pierre Bourdieu e Roger Chartier. In: CHARTIER, Roger (Org.). Práticas da leitura. São Paulo: Estação Liberdade, 1996.

COELHO, M.O. Memórias Literárias de Belém do Pará: o Grupo dos Novos (1946 - 1952). 2003. Tese (Doutorado em Teoria e História Literária) - Instituto de Estudos da Linguagem da Universidade Estadual de Campinas, Campinas, 2003.

Revista Moara, n. 56, vol. 2, jan-jul 2021 ISSN: 0104-0944 
FARES, J. A.; FARES, J. O.; VINAS, R. Texto e pretexto: experiência de educação contextualizada a partir da literatura produzida por autores paraenses. 1. ed. Belém: SEMEC, 1988.

FIGUEIREDO, A.M. Eternos modernos: uma história social da arte e da literatura na Amazônia, 1908-1929. Tese (Doutorado em História) - Instituto de Filosofia e Ciências Humanas da Universidade Estadual de Campinas, Campinas, 2001.

FURTADO, M. "Crimes da terra" na Amazônia, de Inglês de Sousa a Dalcídio Jurandir. In: FURTADO, M.; SALES, G.M.A. Linguagem e Identidade Cultural. João Pessoa: Idéia, 2009.

FORQUIN, J. Saberes escolares, imperativos didáticos e dinâmicas sociais. Teoria \& Educação, Porto Alegre, n. 5, p. 15, 1992.

FRANÇA, M.P.S. Raízes históricas do ensino secundário público na Província do Grão-Pará: o Liceu Paraense. 1997. Dissertação (Mestrado em Filosofia, História e Educação) - Faculdade de Educação, Universidade Estadual de Campinas, Campinas, 1997.

MCLAREN, P. Multiculturalismo crítico. São Paulo: Cortez, 1997.

MEIRA, C. CASTRO, A.; ILDONE, J. Introdução à Literatura no Pará. Belém: CEJUP, 1990.

NUNES, B. Crivo de papel. 2a ${ }^{\text {a }}$ Ed. São Paulo: Ática, 1998.

PRESSLER, G.K. Romantismo na Amazônia? - Palestra No GT da ANPOLL (2009)

Disponível em: < http://docplayer.com.br/7498369-Romantismo-na-amazonia.html> Acesso em: 04 de maio de 2020.

REGO, C.M. Subsídios para a história do colégio estadual "Paes de Carvalho". Belém: EDUFPA/L\&A editora, 2002.

SOUZA, R. S. Histórias invisíveis do Teatro da Paz: da construção à primeira reforma, Belém do Grão-Pará (1869-1890). Belém: Ed. Paka-Tatu, 2010.

ZILBERMAN, R. Literatura e Identidade - O papel formador da história da literatura. IN: FURTADO, M.; SALES,G.M.A. Linguagem e Identidade Cultural. João Pessoa: Idéia, 2009.

ZILBERMAN, R. Estética da recepção e história da literatura. São Paulo: Ed. Ática, 1989.

Revista Moara, n. 56, vol. 2, jan-jul 2021 ISSN: 0104-0944 